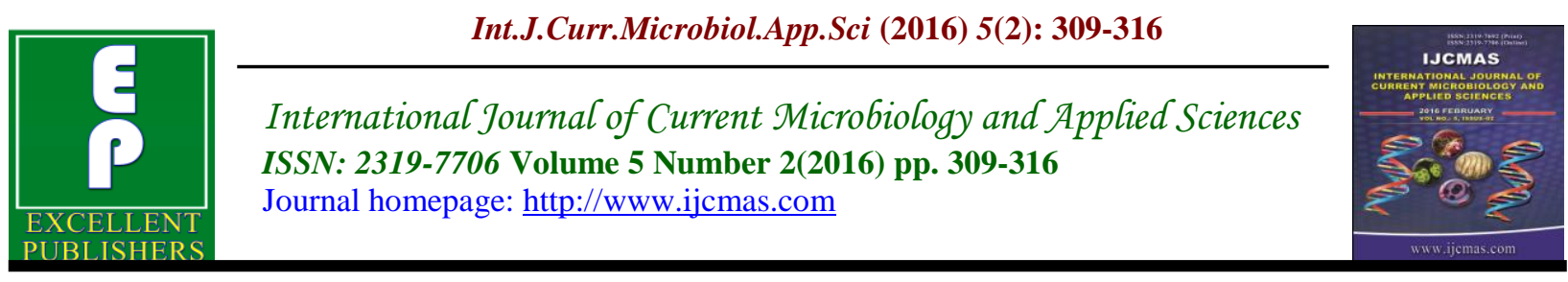

Original Research Article

doi: http://dx.doi.org/10.20546/ijcmas.2016.502.035

\title{
Microbiological Study of Paranasal Sinusitis
}

\author{
Varalakshmi, Y. Umarani and D. Sarada* \\ SF3, Abhinav Enclave, Ballemvari street, Ramavarappadu, Vijayawada, India \\ *Corresponding author
}

\begin{abstract}
A B S T R A C T
Keywords

Sinusitis,

Coagulase

negative,

Positive,

Staphylococci,

Culture.

Article Info

Accepted:

18 January 2016

Available Online:

10, February 2016

Acute Sinusitis is a common infection of the paranasal sinuses and Chronic Maxillary Sinusitis is one of the most common form. A total of 100 samples were collected from patients attending outpatient department of Oto-rhinolaryngology, Government General Hospital, Vijayawada, for Microbiological study. Highest incidence was seen in the age group of 21-30 years (60\%). Out of 100 cases, $96(96 \%)$ were positive on culture of which $87(90.6 \%)$ were positive for bacterial culture, $1(1.04 \%)$ pure fungal and $8(8.33 \%)$ yielded mixed isolates. All the 11 cases of acute sinusitis were culture positive (100\%) and $85(95.6 \%)$ of 89 cases with chronic sinusitis were positive for culture. The predominant organism from bacterial isolates was Coagulase Negative Staphyloccocus 32(40.50\%) followed by Coagulase positive Staphylococcus 22(27.84\%), Pneumococci 10(12.65\%), Beta haemolytic Streptococci 5(6.32\%) and others. The predominant bacterial isolate in Acute Sinusitis were Coagulase Negative Staphylococcus 6(54.54\%) followed by Coagulase Positive Staphylococcus 2(18.18\%), Diphtheroids 2(18.18\%) and Klebsiella pneumoniae 1(9.09\%). In chronic Sinusitis also the commonest isolate was CONS 33(35.86\%) followed by Coagulase Positive Staphylococcus 24(26.08\%), Pneumococci $12(13.04 \%)$ and others. Allergic rhinitis was the commonest predisposing condition and Gentamycin is the drug of choice. Microorganisms causing sinusitis are mostly aerobic and facultatively anaerobic. Isolation and identification of the etiological agent and determination of its susceptibility pattern aids the clinician towards the proper management of the patient and helps in relieving the symptoms in a scientific way.
\end{abstract}

\section{Introduction}

Acute Sinusitis is a common infection of paranasal sinuses and Chronic maxillary sinusitis is one of the most common form. It is encountered in a large number of patients attending Ear, Nose and Throat clinics presenting with variable complaints. It follows an incompletely resolved acute sinusitis, but may appear insidiously following tooth infection. Early diagnosis and treatment of chronic maxillary sinusitis is essential not only to prevent the serious intracranial and orbital complications, but also to relieve the patient from constant excruciating headache and other intolerable symptoms.

The sinus infection may cause inflammation of Pharynx, Larynx, Bronchi and Gastric 
symptoms via constant descending infection. These conditions fail to respond to treatment unless the primary infection is recognized and treated early. Maxillary sinusitis is usually diagnosed on clinical and radiological grounds. Identification of causative organisms (bacteria, fungi or viruses) in the maxillary sinus contents is essential for proper mode of treatment.

Paranasal sinusitis can be categorised on the basis of duration of symptoms into acute and chronic sinusitis. The bacterial organisms involved in acute sinusitis are predominantly aerobic and in chronic Sinusitis anaerobic bacteria play a significant role.

In the pre antibiotic era rapid surgical intervention was the main stay in the management of sinusitis. With advent of antibiotics, indication of surgery is reduced to maximum extent. Management of chronic maxillary sinusitis has changed considerably owing to the rapid advances in diagnostic techniques like radiography, ultrasonography, synoscopy and improved bacterial cultural and antibiotic sensitivity techniques.

With the rapid industrialization, overcrowding of urban areas and atmospheric pollution, the incidence of sinusitis has raised. Investigations have linked allergy as a contributing factor in $25 \%$ to $30 \%$ of patients with acute maxillary sinusitis, with an expected incidence of $14 \%$ to $17 \%$ in control subjects.

The bacterial flora of sinus disease has been ever changing and the development of antibiotic resistance to the commonly used antibiotics necessitated the need for the use of higher antibiotics after bacteriological study and antibiotic sensitivity. Antibiotic susceptibility testing is essential to determine the susceptibility and resistance pattern of the causative organisms encountered in sinusitis.

The present study is aimed at isolation and identification of most common pathogen involved in the causation of acute and chronic Paranasal Sinusitis and their susceptibility to chemotherapeutic agents in and around Vijayawada.

\section{Materials and Methods}

The study group consists of 100 patients attending ENT Department both outpatient and inpatients of Govt. General Hospital, Vijayawada and a control group of 25 asymptomatic individuals attending to $\mathrm{OP}$ are included over a period of 13 months. Details of clinical history and analysis were documented. The study includes individuals with acute sinusitis as well as patients with chronic paranasal sinusitis mostly of chronic maxillary sinusitis. Endoscopic specimens were collected from nasal mucosa, maxillary ostium and tested for bacteriological isolates by standard microbiological techniques.

Specimens were collected from maxillary ostium during endoscopy, under 4\% local Xylocaine installation. Four swabs were collected under aseptic precautions, with one swab inoculated into Robertsons Cooked Meat medium and transported to the department of Microbiology, Siddhartha Medical College, Vijayawada for processing. Other three swabs were used for direct smear preparation, bacteriological inoculation and fungal culture.

Antibiotic susceptibility test was done by standard technique of disc diffusion method using filter paper disc of $6.0 \mathrm{~mm}$ for all the bacterial isolates.

\section{Results and Discussion}

Present study includes 100 cases of Paranasal sinusitis attending the Department 
of Oto-rhinolaryngology of Government General Hospital, Vijayawada. Of these, 11 were Acute and 89 were of chronic sinusitis. Nasal swabs were collected from 25 asymptomatic individuals and were processed by standard microbiological techniques.

Out of 100 cases, $96(96 \%)$ were positive on culture of which $87(90.6 \%)$ were positive for bacterial culture, $1(1.04 \%)$ positive for pure fungal and $8(8.33 \%)$ yielded mixed isolates. All the 11 cases of acute sinusitis were culture positive (100\%) and 85(95.6\%) of 89 cases with chronic sinusitis were positive for culture.

Of the study group, 51 were males of which $48(94.12 \%)$ were culture positive and of 49 females, 48(97.95\%) were positive. The predominant age group was 21 - 30 years followed by $31-41$ years and two cases less than 10 years.

Of the 100, 96(96\%) were positive on culture with 87(90.62\%) Bacterial isolates and $9(9.37 \%)$ Fungal isolates. The predominant organism from bacterial isolates was Coagulase Negative Staphyloccocus 32(40.50\%) followed by Coagulase positive Staphylococcus 22(27.84\%), Pneumococci 10(12.65\%), Beta haemolytic Streptococci 5(6.32\%), Klebsiella pneumoniae 4(5.06\%), Diphtheroids 3(3.79\%), Pseudomonas aeruginosa 2(2.53\%) and Micrococci $1(1.26 \%)$. Mixed isolates includes Coagulase negative Staphylococcus with Micrococci 3(37.50\%), CONS and Beta haemolytic Streptococci 1(12.5\%), CONS and Klebsiella pneumoniae 1(12.5\%), CONS and Diphtheroids 1(12.5\%), Coagulase Positive Staphylococcus and Pseudomonas aeruginosae 1(12.5\%) and the single fungal isolate is Candida albicans. The mixed bacterial and fungal isolates are Coagulase Positive Staphylococcus and Aspergillus in 2 cases, one with Coagulase Positive Staphylococcus and Heterosporum, CONS along with Penicillium and Mucor in one case each and Pneumococci with Aspergillus and Alternaria one case each.

The predominant bacterial isolate in Acute Sinusitis are Coagulase Negative Staphylococcus 6(54.54\%) followed by Coagulase Positive Staphylococcus 2(18.18\%), Diphtheroids 2(18.18\%) and Klebsiella pneumoniae 1(9.09\%). In chronic Sinusitis also the commonest isolate was CONS 33(35.86\%) followed by Coagulase Positive Staphylococcus 24(26.08\%), Pneumococci 12 (13.04\%), Beta haemolytic Streptococci 7(7.60\%), Diphtheroids $5(5.43 \%)$, Klebsiella pneumoniae 4(4.43\%), Micrococci 4(4.43\%) and Pseudomonas aeruginosae $3(3.26 \%)$.

As seen from the Sensitogram of the various isolates, Gentamycin could be the drug of choice as almost all pathogens isolated except Pseudomonas aeruginosae were highly sensitive to Gentamycin.

The commonest predisposing conditions as in Acute Sinusitis was Allergic rhinitis $6(54.54 \%)$ followed by dental disease $3(27.27 \%)$ and Upper respiratory infection in $2(18.18 \%)$. Deflected Nasal septum $17(19.10 \%)$ was the predominating cause in chronic sinusitis followed by obstruction with nasal polyp or hypertrophic turbinate in $13(14.60 \%)$, Allergic rhinitis $12(13.48 \%)$, upper respiratory tract infections Pharyngitis or Tonsillitis 8(8.98\%), Dental diseases $7(7.86 \%)$ and CSOM in $3(3.37 \%)$. Vague systemic manifestations like fever in $29(32.58 \%)$ and Headache was constant complaint in both Acute and Chronic cases.

All the controls were positive on bacterial culture and yielded mixed bacterial flora and no fungal isolates were obtained. Polymicrobial growth was seen in 24 control 
group with the predominating organism as Diphtheroids 24(96\%) followed by CONS $3(12 \%)$, Beta haemolytic Streptococci 2(8\%), Pneumococci 1(4\%) and Micrococci $1(4 \%)$. All the isolates were highly sensitive to Penicillin, Tetracycline, Erythromycin along with Ciprofloxacin and Gentamycin in contrast to the isolates from clinical cases which showed high resistance of isolates from cases of sinusitis.

Table.1 Age Wise Distribution

\begin{tabular}{|l|c|c|c|c|c|c|c|c|c|}
\hline $\begin{array}{c}\text { Age in } \\
\text { years }\end{array}$ & $\begin{array}{c}\text { Acute } \\
\text { No. test }\end{array}$ & Positive & $\%$ & $\begin{array}{c}\text { Chronic } \\
\text { No. Test }\end{array}$ & Positive & $\%$ & $\begin{array}{c}\text { Total } \\
\text { tested }\end{array}$ & Positive & $\%$ \\
\hline $0-10$ & 2 & 2 & 100 & - & - & - & 2 & 2 & 100 \\
\hline $11-20$ & 3 & 3 & 100 & 15 & 15 & 100 & 18 & 18 & 100 \\
\hline $21-30$ & 3 & 3 & 100 & 27 & 26 & 96.29 & 30 & 29 & 96.66 \\
\hline $31-40$ & 3 & 3 & 100 & 19 & 18 & 94.73 & 22 & 21 & 95.45 \\
\hline $41-50$ & - & - & - & 16 & 15 & 93.75 & 16 & 15 & 93.75 \\
\hline $51-60$ & - & - & - & 8 & 7 & 87.5 & 8 & 7 & 87.5 \\
\hline Above 60 & - & - & - & 4 & 4 & 100 & 4 & 4 & 100 \\
\hline
\end{tabular}

Table.2 Microbial Flora Isolated from 100 Samples of Paranasal Sinusitis

\begin{tabular}{|l|l|c|c|}
\hline S.No & Organism only bacterial isolates & Number & Percentage \\
\hline 1 & Coagulase Negative Staphylococci & 32 & 40.50 \\
\hline 2 & Coagulase Positive Staphylococci & 22 & 27.84 \\
\hline 3 & Streptococcus pneumoniae & 10 & 12.65 \\
\hline 4 & Beta Hemolytic Streptococci & 5 & 6.32 \\
\hline 5 & Klebsiella pneumoniae & 4 & 5.06 \\
\hline 6 & Diphtheroids & 3 & 3.79 \\
\hline 7 & Pseudomonas aeruginosae & 2 & 2.53 \\
\hline 8 & Micrococci & 1 & 1.26 \\
\hline & Total & 79 & \\
\hline
\end{tabular}

Figure.1

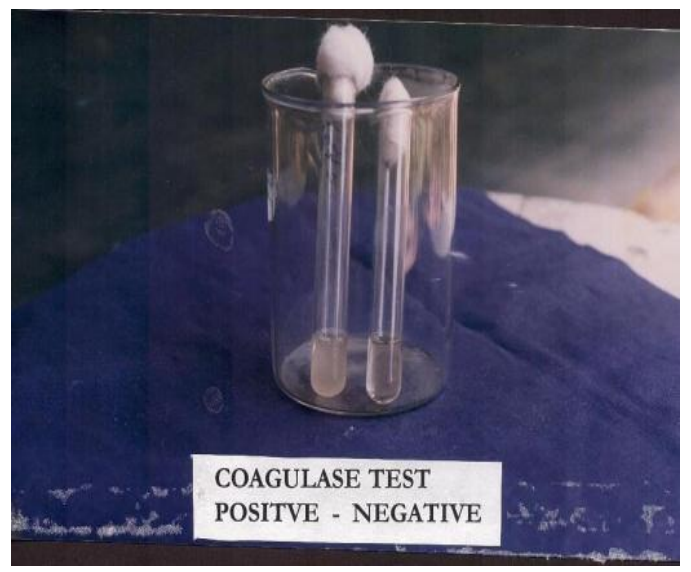


Table.3 Mixed Bacterial Isolates

\begin{tabular}{|c|c|c|c|}
\hline S.No & Mixed Bacterial Isolates & Number & Percentage \\
\hline 1 & $\begin{array}{l}\text { Coagulase negative Staphylococci + } \\
\text { Micrococci }\end{array}$ & 3 & 37.50 \\
\hline 2 & $\begin{array}{l}\text { Coagulase Positive Staphylococci }+ \\
\text { Pseudomonas aeruginosa }\end{array}$ & 1 & 12.50 \\
\hline 3 & $\begin{array}{l}\text { Coagulase Positive Staphylococci + } \\
\text { Diphtheroids }\end{array}$ & 1 & 12.50 \\
\hline 4 & $\begin{array}{l}\text { Coagulase Negative Staphylococci + } \\
\text { Beta hemolytic Streptococci }\end{array}$ & 1 & 12.50 \\
\hline 5 & $\begin{array}{l}\text { Beta hemolytic Streptococci + } \\
\text { Diphtheroids }\end{array}$ & 1 & 12.50 \\
\hline \multirow[t]{2}{*}{6} & $\begin{array}{l}\text { Coagulase negative Staphylococci + } \\
\text { Klebsiella pneumoniae }\end{array}$ & 1 & 12.50 \\
\hline & Total & 8 & \\
\hline
\end{tabular}

Figure.2

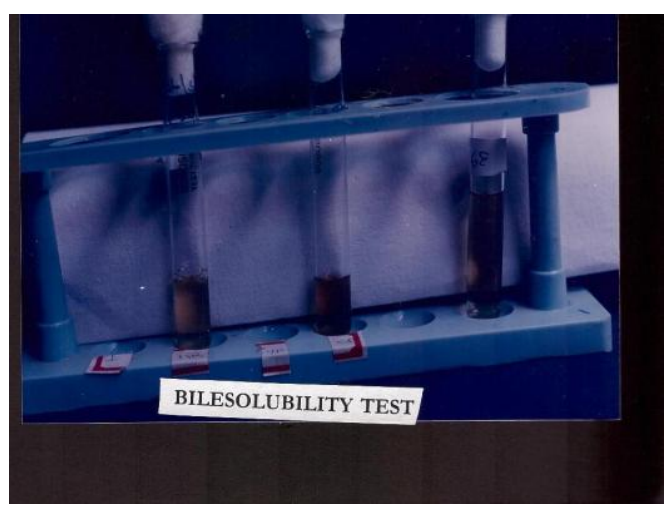

Figure.3

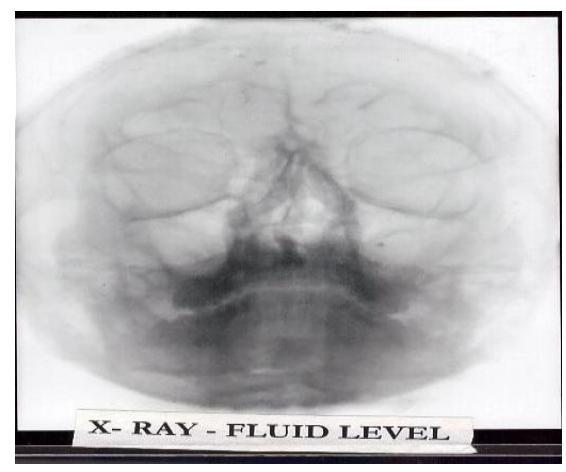


Figure.4

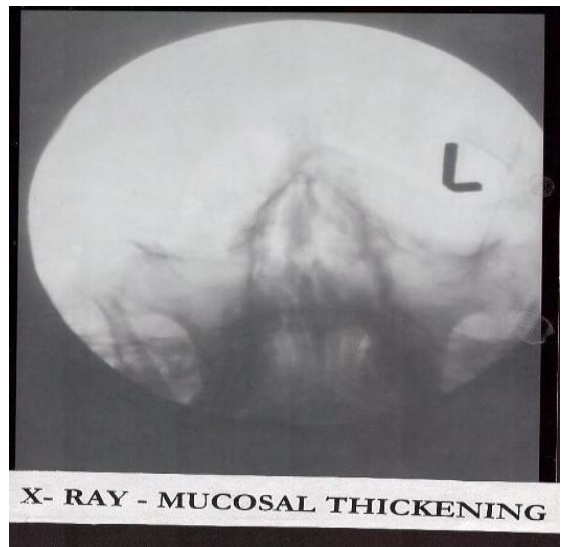

Sinusitis is a common medical problem encountered in patients attending the department of otorhinolaryngology. The microbial flora of acute and chronic sinusitis has been variously reported by different workers, who attempted to find out the flora of nasal cavity and etiological agents of sinusitis. Hundred samples obtained by endoscopic examination and a control group of 25 individuals were considered for the study and an attempt is made to know the microbial etiology in and around Vijayawada.

Common predisposing factor in acute sinusitis was allergic rhinitis with nasal obstruction (54.54\%) followed by dental diseases $(27.27 \%)$ and upper respiratory infections (18.18\%) in our study. NewMen et al. (1997) reported relation of allergic rhinitis with sinusitis in $78 \%$ of patients, Itzakh Brook et al. (1982) and Berry reported $18 \%$ to apical infections and $30 \%$ to dental abscess and Wald ER (1985) reported that upper respiratory infections constituted only 3 to $5 \%$ of acute sinusitis. Pain in the region of cheeks and headache was the most common symptom along with vague constitutional symptoms like malaise, weakness, anorexia etc and this correlates with studies by Karthyn L. Evans (1994),
Elme W. Koneman, Stephen D Allen et al. and Itzahak Brook (1995).

High positivity on culture was seen in the age group of $21-30$ years $(96.6 \%)$ followed by $31-40(95.4 \%)$ and $41-50(93.75 \%)$ and no sex preponderance was noticed. Jousimies -Somer et al. (1988) reported more than $90 \%$ of isolation between age group of 17-30 years. Bacteriological study of functional endoscopic sinus surgery aspirates from maxillary sinuses revealed isolation rate of aerobic bacterial isolates as $90.4 \%$ and anaerobic $14.2 \%$ and the common aerobe isolated was Coagulase negative Staphylococcus (87\%) as reported by Aral M Keles E Kaygusuz.

Bacteriological study of chronic sinusitis using a swab and mucosal specimen, culture positivity was $96 \%$ and our study correlates with Itzhak brook (1989) and Erkan et al (1994) with a positivity rate of $92 \%$. Pure bacterial isolates were seen in $79(82.29 \%)$ and mixed bacterial isolates in $9(9.37 \%)$ pure fungal in $1(1.04 \%)$ and mixed bacterial and fungal in $8(8.3 \%)$ in our study. Many studies documented polymicrobial nature and mixed growth was found in $36 \%$ and $31 \%$ cases as reported by Erkan et al. (1994) and Itzhak brook et al. (1994). Coagulase 
negative Staphylococcus was the predominant organism 32(40.50\%) isolated in our study both in single and mixed bacterial isolates followed by Coagulase positive Staphylococci 22(27.84\%), Streptococcus pneumoniae 10(12.60\%), Beta haemolytic Streptococci 5(6.32\%) and others and this correlates with studies by Bent J.P.Kohan FA (1994), Shazro RD Swain RE (1995) and Serrano E et al. (2001) who obtained Coagulase negative Staphylococci (36\%) as the commonest isolate followed by Staphylococcus aureus (25\%), Streptococcus viridians $(8.3 \%)$ and Anaerobes (6.4\%). No anaerobes were isolated in our study. Coagulase negative Staphylococci were normally considered as part of normal flora of the nose but they may be responsible for causation of sinusitis. However, Coagulase negative Staphylococci has been implicated as a virulent pathogen in neutropenic and neonatal sepsis, endocarditis and Urinary tract and burn related infections by Sidebottom DG, Freeman J Platt R Epstein MF (1990), Molnar CHevessay Z (1994).

Antibiotic sensitivity testing of the isolates was done and Coagulase negative Staphylococci isolated from patients was resistant to common antibiotics like Penicillin, Cephalexine, Amikacin, Ampicillin, Erythromycin and others compared to the organism obtained in the control group showing high susceptibility to many antibiotics tested. These findings suggest that CONS acquired in patients with sinusitis may infect ne a pathogen and these results are consistant with findings of Hoyt IO that $46 \%$ of the bacterial isolates from patients with chronic sinusitis were CONS of which $35 \%$ were resistant to commonly used antibiotics. In the present study, most of the isolates were highly susceptible to Gentamycin (80.76\%) and Chloramphenicol $(80.76 \%)$ followed by Imepenum and Co- trimoxazole. The susceptibility pattern reported by various authors was varying and this may be attributed to the predominant organism, the particular geographical distribution and also varying susceptibility nature of the organisms. The role of indiscriminate use of antibiotics also should not be forgotten as a cause of varying susceptibility. Hence the antibiotic sensitivity pattern of the isolates is a must to guide the clinician towards proper treatment of Sinusitis.

\section{Acknowledgments}

We are sincerely thankful to Dr. M. RajaRajeswari madam for her guidance and advice in successfully completing this project.

\section{References}

Anodori G., BastianiL et. al.; "Rhinology"; 1986 Dec, 24 (4): 257-64.

Aral M, Keres E, Kaygusuz I; American Journal of Otolaryngology 2003 May - June: 24(3): 163-168, Department of Microbiology Sutcu Imam University, Kahramanmaras, Turkey.

Axelsson, A Broson JE, "Microbiology of acute and chronic sinusitis"; Otolaryngology head and neck surgery July 2002; 1973, 83, 200311.

B. Kremer, ER Soudijin - Dept. of Oto rhino laryngology, Head and Neck surgery; 2001. Reported in EUR Arch Oto rhinolaryngology.

Bauer, AW Kirby W.M.M. Sherris, J. et al.; "Antibiotic Susceptibility testing by a single disc method"; 1966; AMJ Clinical pathology 45:493 (Bailey and Scott's Diagnostic Microbiology).

Benninger MS, Anon J, Mabry RL, "The Medical management of 
rhinosinusitis"; 1997; Otolaryngology Head Neck surgery 117;47-49.

Benninger MS., Appelbaum TC., Denneny JC., et al; "Oto laryngol, Head, Neck surgery"; 2002, July; 127 (1):7 - 12.

Brook 1; "Aerobic and Anaerobic bacterial flora of nasal maxillary sinus. Laryngo scope"; 1981; 91, 372-375.

Brook 1; "Bacteriology of Chronic maxillary sinusitis in adults"; 1989; Ann. Otolaryngol 98: 426 -428.

Brook I, Frazier EH, Floote PA- Department of Pediatrics, Naval Hospital, Bethesa MD USA.; "Microbiology of Chronic maxillary sinusitis comparision between Specimens obtained by sinus endoscopy and by surgical drainage"; 1997 May; J. Medi Microbiol, 46(5):430-2.

Chan J \& Hadley J; "Microbiology of Chronic rhino sinusitis"; 2001; Ear, Nose, Throat J-80: 143-145.

Erkan M, Aslam T, Ozcan M, KOC N; "Bacteriology of antrum in adults with chronic maxillary sinusitis, Laryngoscope; 1994; 104: 321-324.

Ferguson BJ. Johnson JT; "Allergic rhinitis and rhino sinusitis"; Postgraduate medicine 1999, 105: 55-58, 61,64.

Finegold SM, FlynnMJ. Rose, FY. Jousimies-Somer et al; 2002; clinical infectious dis, 35, 428-433.

Jiang R.S Hsu, CY, Leu, J.F; "Bacteriology of ethmoid sinus in chronic sinusitis;
1997; American journal of Rhinology 11: 133-137.

Jiang RS, LINJF, HSUCY; "Bacteriology of Chronic maxillary sinusitis in relation to sinoscopy appearance"; 2002 Sep. Oct.; AMJ Rhinol: 16 (5): 249-53.

John Ballantyntyne, John Groves; ScottBrown's diseases of Ear, Nose and Throat $4^{\text {th }}$ edition Vol 1 "Basic sciences", (Text book).

Kremer B, Jacobes JA, SoudijnER, Vander Ven AJ; "Clinical value of bacteriological examination of nasal and paranasal mucosa in patients with chronic sinusitis"; 2001; EUR Arch Otolaryngology 258. (5): 220225.

Murat Aral MD, Erokeles MD, lfronkaygusuz; "The Microbiology of Ethmoid and maxillary sinus patients with chronic sinusitis"; 2093; AMJ of Otolaryngology May 2003 Vol. 24, No.3.

Rajiv Arora et al; "Bacteriology of chronic maxillary sinusitis with special reference to anaerobes"; 1993; Indian journal of Medical Microbiology; 11(3):206,209.

Serrano, E., J, Percodani J, Euro-coste et al; 2000; The journal of laryngology and otology March 2001 vol 115, P- 3: 184-189.

\section{How to cite this article:}

Varalakshmi, Y. Umarani and D. Sarada. 2016. Microbiological Study of Paranasal Sinusitis Int.J.Curr.Microbiol.App.Sci.5(2): 309-316. doi: http://dx.doi.org/10.20546/ijcmas.2016.502.035 